Article

\title{
Mosses Like It Rough-Growth Form Specific Responses of Mosses, Herbaceous and Woody Plants to Micro-Relief Heterogeneity
}

\author{
Benjamin F. Leutner ${ }^{1,2}$, Manuel J. Steinbauer ${ }^{1, *}$, Carina M. Müller ${ }^{1}$, Andrea J. Früh ${ }^{1}$, \\ Severin Irl ${ }^{1,3}$, Anke Jentsch ${ }^{3}$ and Carl Beierkuhnlein ${ }^{1}$
}

1 Biogeography, BayCEER, University of Bayreuth, Bayreuth 95440, Germany;

E-Mails: b.leutner@gmx.de (B.F.L.); Carina.M.Mueller@web.de (C.M.M.);

frueh.andrea@googlemail.com (A.J.F.); severin.irl@uni-bayreuth.de (S.I.);

carl.beierkuhnlein@uni-bayreuth.de (C.B.)

2 Biogeographical Modelling, BayCEER, University of Bayreuth, Bayreuth 95440, Germany

3 Disturbance Ecology, BayCEER, University of Bayreuth, Bayreuth 95440, Germany;

E-Mail: anke.jentsch@uni-bayreuth.de

* Author to whom correspondence should be addressed; E-Mail: manuel.steinbauer@uni-bayreuth.de; Tel.: +49-921-55-2211; Fax: +49-921-55-2315.

Received: 30 November 2011; in revised form: 20 January 2012 / Accepted: 1 February 2012 / Published: 10 February 2012

\begin{abstract}
Micro-relief heterogeneity can lead to substantial variability in microclimate and hence niche opportunities on a small scale. We explored the relationship between plant species richness and small-scale heterogeneity of micro-relief on the subtropical island of La Palma, Canary Islands. Overall, we sampled 40 plots in laurel and pine forests at four altitudinal bands. Species richness was recorded separately for various growth forms (i.e., mosses, herbaceous and woody plants). Site conditions such as altitude, slope, aspect, and tree density were measured. Micro-relief heterogeneity was characterized by surface structure and a subsequently derived surface heterogeneity index. The effect of micro-relief heterogeneity on species richness was analysed by means of linear mixed effect models and variance partitioning. Effects of micro-relief heterogeneity on species richness varied considerably between growth forms. While moss richness was affected significantly by micro-relief heterogeneity, herbaceous and woody plants richness responded mainly to larger-scale site conditions such as aspect and tree density. Our results stress the importance of small-scale relief heterogeneity for the explanation of spatial patterns of
\end{abstract}


species richness. This poses new challenges as small-scale heterogeneity is largely underrepresented, e.g. with regard to its application in species distribution models.

Keywords: biodiversity; habitat heterogeneity; micro-topography; topographic variability; northernness; species diversity; Bitterlich; altitudinal gradient; laurel forest; climate change

\section{Introduction}

Projections on future developments based on current species distribution models reveal substantial elevational shifts of occurrences of plant species under climate change [1,2]. This could drive many species - unable to reach climatically suitable habitats - to the brink of extinction [3]. However, these models do not include small-scale differences in relief-heterogeneity [4]. Scherrer and Körner [5] highlighted the role of thermal differences on the metre-scale in alpine ecosystems that even exceed the IPCC temperature projections for the end of this century [6]. A mosaic of microclimatic conditions could thus create refuges and stepping stones in a warmer climate within just a few metres distance from the previous location of a plant population [7]. This implies that according to the niche theory [8], more species should be found in heterogeneous environments compared to homogenous environments, because more spatial and ecological niches are available. A positive correlation has been found between topographic variability, site heterogeneity and species richness, e.g. [9-11]. Nevertheless in a recent review Lundholm [12] showed that the relationship between plant species richness and environmental heterogeneity is not that straightforward as even negative relationships have been reported. The relationship seems to be most pronounced in communities with medium productivity [13]. Relief heterogeneity is an important factor regulating soil moisture [14], microclimate [7] and plant available nutrients $[15,16]$. Also the intensity of stress (e.g. soil erosion or thickness of a poorly decomposable litter layer) is influenced by relief heterogeneity [17]. Habitats that incorporate a heterogeneous relief, provide a greater number of ecological niches and thus can be expected to host a highly diverse species composition [18]. This is confirmed at the micro- and meso-scale [12]. Competitive exclusion is reduced in heterogeneous environments as they provide more diverging abiotic conditions for growth or vary stronger in their disturbance frequency or magnitude $[19,20]$. In addition, small-scale genetic differentiation in plants occurs commonly within micro-environmental heterogeneity, at small spatial scales [21]. As plants differ in their ability to respond to small-scale variability in abiotic conditions, it is assumed that mosses and herbaceous plants can profit more by micro-relief heterogeneity compared to trees and bushes [22].

In ecological studies, especially when it comes to theory, relief heterogeneity is integrated with environmental and biotic heterogeneity. Terminology is often imprecise using "habitat heterogeneity" [23] or "complexity" [24,25] interchangeably. While this may be justified in theoretical concepts, more specific approaches are required in empirical studies. In addition, relief heterogeneity is mostly detected via rather general and simplistic variables such as elevation, slope or aspect [15].

To date, studies that address the effect of relief heterogeneity on species richness focused on regional to landscape scales (i.e., with a grain often much larger than one $\mathrm{km}^{2}$, e.g. [26]), although Hofer et al. [10] demonstrated that small-scale topographic variability ( $25 \mathrm{~m} \mathrm{scale})$ can be one of the 
major explanatory variables of species richness in gradient dominated landscapes and is predicted to become even more important in a prospective warmer climate [7]. Moreover, it has not been tested whether this relationship is modified by elevation. Studies that apply a fine spatial grain are missing, and the challenges and knowledge gaps especially at this scale are limiting the quality of climatic envelope approaches. Most likely this is due to the fact that at this scale spatial heterogeneity has to be measured and cannot be derived from existing geo-information such as topography.

To investigate the linkage of micro-relief and species richness we conducted a vegetation survey on La Palma, Canary Islands. This island is well suited for this purpose as it offers a large plant species pool [27] as well as a wide altitudinal range [28]. We focused on forested areas, as these provide continuous natural vegetation along the altitudinal gradient. Non-forested ecosystems in contrast are restricted to the subalpine mountain peaks and the lower altitudes.

The first hypothesis tested in this study is that small-scale micro-relief heterogeneity positively affects species richness. The supporting effect of micro-relief heterogeneity on species richness is expected to be stronger in higher altitudinal bands compared to lower ones as relief heterogeneity has been suggested to increase with altitude [10]. Additionally, in the increasingly harsh environments of high altitudes plants would profit more from the availability of micro-climatic refuges. Our second hypothesis refers to plant growth forms. Species richness of mosses and herbaceous plants are hypothesised to be influenced more strongly by small-scale micro-relief heterogeneity than the richness of woody species (see also [22]).

\section{Background and Methods}

\subsection{Study Area}

The study site is located on the volcanic Island of La Palma, Canary Island archipelago, Spain $\left(28^{\circ} 54^{\prime} \mathrm{N} ; 1^{\circ} 50^{\prime} \mathrm{W}\right)$. La Palma comprises an area of approximately $700 \mathrm{~km}^{2}$ and rises from sea level to 2423 m.a.s.1., thus, resulting in very steep slopes. The island is characterized by a strong NE-SW gradient in rainfall and water availability with a strongly contrasting altitudinal zonation mainly due to a thermic inversion and the topographic barrier effect of the mountains. Ascending humid air masses of the trade-winds (NE winds) frequently form a stratocumulus layer in altitudes ranging from $800 \mathrm{~m}$ up to the seasonally varying thermal inversion at 1,000 to $1,500 \mathrm{~m}[29,30]$. This climatic setting supports a distinct vegetation zonation from semi-arid succulent shrub to evergreen laurel forests, pine forests and subalpine shrub vegetation [31].

The two prevailing natural forest types incorporated in this study were laurel and pine forest. The former is limited to humid conditions with precipitation provided by the stratocumulus layer and extends from 500 to $1200 \mathrm{~m}$. The laurel forest is concentrated on the NE-facing slopes. It comprises about 20 tree species, which form a dense canopy, leading to low light availability within the stand and a moderate understorey consisting of shrubs, herbs, ferns and moss species. Characteristic evergreen broadleaved woody species (nomenclature following [32]) are Apollonias barbujana (Cav.) Bornm., Laurus novocanariensis Rivas-Mart., Lousa, Prieto, Días, Costa and Aguiar, Ocotea foetens (Aiton.) Baill., Persea indica (L.) Spreng., Morella faya (Aiton) Wilbur, Viburnum rigidum Vent., Ilex canariensis Poir., Sonchus palmensis (Sch. Bip.) Boulos, and Hedera canariensis Willd. 
The pine forest is dominated by one tree species; the Canary endemic Pinus canariensis Sweet ex Spreng. Although the forest structure is more open than the laurel forest and much light is available, the abundance of the understorey vegetation is low and a thick layer of needle litter covers the ground. Common understorey species are Cistus symphytifolius Lam., Pteridium aquilinum (L.) Kuhn in Kerst., Adenocarpus foliolosus (Aiton) DC., and A. viscosus ssp. spartioides (Willd.) Webb and Berthel. Pine forests occur between 1200 to $2100 \mathrm{~m}$ and are repeatedly subject to natural but also anthropogenic fires.

\subsection{Sampling Design}

The sampled sites were located on the northeastern slopes of La Palma. Sampling took place in April 2011. We sampled in four altitudinal bands (550, 750, 1,450, and 1,600 m.a.s.1.) allowing for an altitudinal range of $+/-50 \mathrm{~m}$ in each band depending on local accessibility. Within each altitudinal band 10 plots were sampled.

For every altitudinal band a point of origin was fixed from which we walked in random directions determined by a random number generator. We stopped when all predefined suitability criteria were met in order to ensure the comparability between plots. Plots were considered suitable if slopes were shallower than $25^{\circ}$, had, a minimum distance of $5 \mathrm{~m}$ to tracks as well as $30 \mathrm{~m}$ between the plots.

We used rectangular plots $(5 \times 8 \mathrm{~m})$ oriented parallel to the slope. For each plot GPS coordinates, aspect, altitude, and slope of the two downhill facing sides of the plot ( $\beta$ in Figure 1) were recorded. We used the Bitterlich-stick method ( $0.5 \mathrm{~cm}$ angle; $50 \mathrm{~cm}$ stick), a measure of basal area (see e.g. [33]) to obtain an index of tree density. All plant species within the plot were recorded and classified to the basic growth forms: mosses, herbaceous (including herbs, grasses and ferns) and woody plants (including shrubs and trees).

Figure 1. Within-plot sampling design: four transects of seven measurements each, resulting in 22 regular measurements (blue dots). Original sampling was performed from an imaginary plane $1.80 \mathrm{~m}$ above the plot and parallel to the slope. Values were corrected to equal those, which would have been obtained if they had been measured from a horizontal plane (green dots). Red dots emphasize the measurements of one transect.

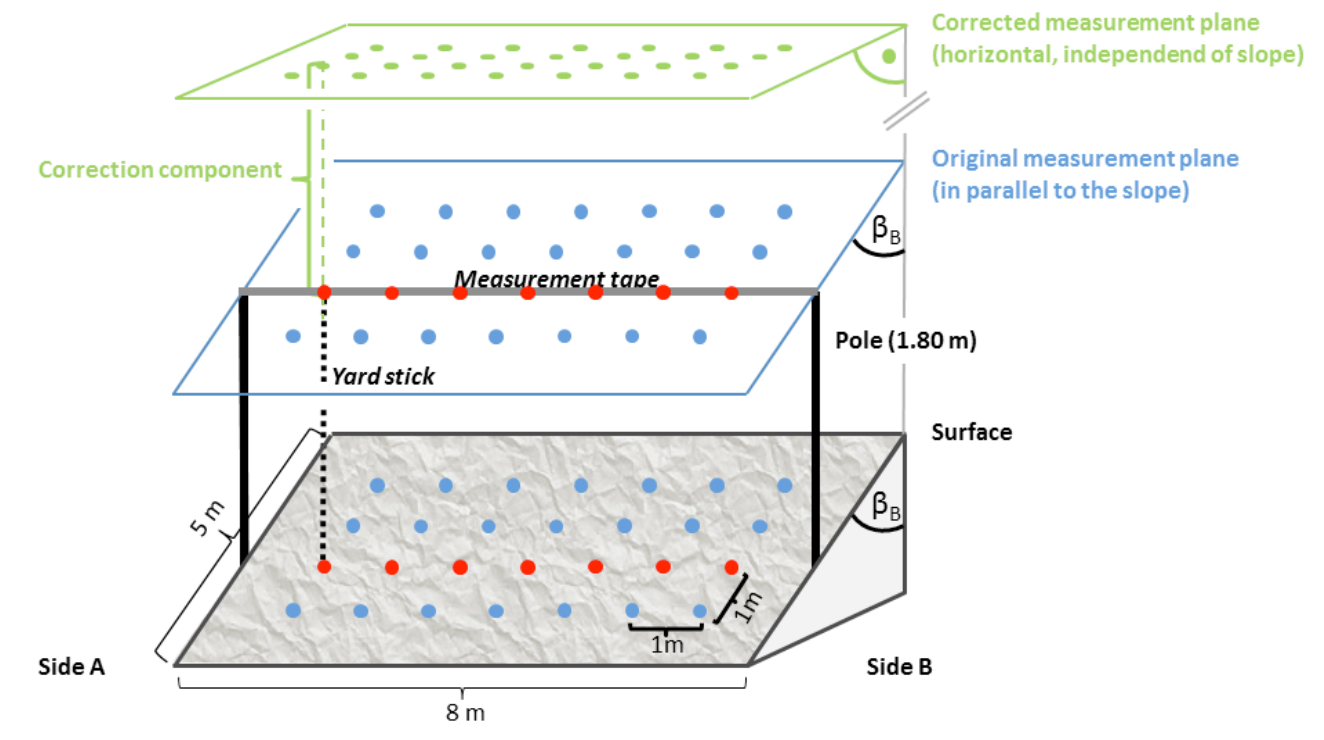




\subsection{Micro Relief Heterogeneity}

We aimed to develop a rapid and repeatable technique suitable for assessment of micro relief heterogeneity in the field. As the very dense understorey prevented application of the classical chain method [34] or theodolite measurements, the deviance of the relief from a plane surface was measured.

For the measurement of deviance, the micro-relief elevations within the plot were measured along four transects parallel to the slope (see Figure 1). For each transect we spanned a scaled tape in $1.80 \mathrm{~m}$ height and measured the perpendicular distance to the surface using a yardstick at every metre. Transects were spaced in one metre distances in order to achieve a regular grid of four times seven measurements.

The measured perpendicular distance values were corrected for the slope in order to ensure that directional effects of heterogeneity would not be lost due to the way of measuring only parallel to the slope. Therefore, the angles in the slope direction were used to calculate the required offset correction component (Equation 1). Since the angles could differ on the two sides of the plot they were both included with a weighting factor, which decreased linearly with distance of the measured point to the respective side of the plot, i.e., a weighted average:

$$
h_{\text {corrected }}=h_{\text {old }}+w_{A} * \sin \left(\beta_{A}\right) * d+w_{B} * \sin \left(\beta_{B}\right) * d
$$

with $h_{\text {old }}$ being the measured height, $w$ being the weighting factors, $\beta$ being the slope angle, $d$ the distance of the transect from the origin and subscript $A$ being the left side of the plot and $B$ the right side, respectively. The weighting factors are $w_{A}=\{1 ; 5 / 6 ; \ldots ; 0 \mid$ for $\mathrm{A} \rightarrow \mathrm{B}\}$ and vice versa for $w_{B}$. The slope parallel angles were small, i.e., smaller than $6^{\circ}$, and hence neglected. The resulting corrected values correspond to hypothetical measurements from a horizontal plane (Figure 1).

Based on artificially created test surfaces, e.g. very smooth surfaces vs. very rough surfaces, we developed the following set of heterogeneity indices: "Index 1" was calculated based on a moving window which encompassed four measurement points and was shifted across the relief data. For each window the standard deviation of the contained points was calculated. Subsequently, the standard deviations of all windows were averaged. For "Index 2" the standard deviation of each measurement transect was calculated and averaged across the four transects. "Index 3" was the elevational range between total minimum and total maximum of all measured points. Finally, "Index 4" was calculated as the sum of the Euclidean distances between successive pairs of measurement points within each transect, that were eventually summed over all transects.

Initial testing of the four statistical indices of relief heterogeneity on a set of artificial test surfaces (Figure 2) revealed two suitable indices. Both "Index 1" based on moving window standard deviations and "Index 4" representing the total transect-wise surface length, achieved the desired property of increasing values with increasing degree of small-scale heterogeneity (Figure 3). "Index 2" and "Index 3" were not sensitive to changes in small-scale heterogeneity and hence discarded. Since "Index 1" and "Index 4" were highly correlated (Pearson correlation coefficient $=0.97$ ) all further analyses were restricted to using "Index 1" only. Statistical measures similar to "Index 1" to quantify topographic variability on various scales based on digital elevation models have been used and tested frequently before (e.g. [35-38]). Note that there is collinearity between small-scale heterogeneity and surface area that cannot be disentangled [39]. 
Figure 2. Artificial test surfaces, which were used to select sensitive indices of small-scale micro-relief heterogeneity: (a) perfectly smooth surface; (b) perfectly smooth surface with one step of $0.8 \mathrm{~m}$; (c) mixture of perfectly smooth surface and two big humps (range $0.8 \mathrm{~m})$; (d) rough surface (range: $0.3 \mathrm{~m}) ;(\mathbf{e})$ even mixture of perfectly smooth and very rough surface (range $0.8 \mathrm{~m}$ ); (f) very rough surface (range: $0.8 \mathrm{~m}$ ).

(a)

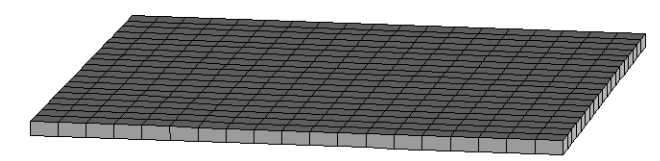

(c)

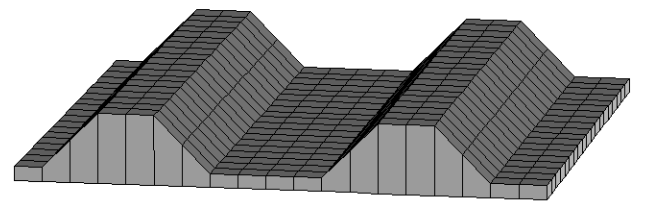

(e)

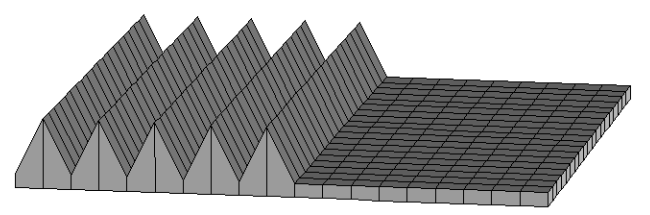

(b)

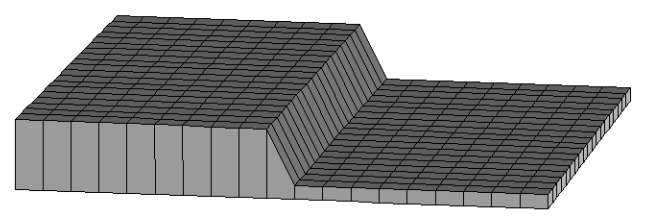

(d)

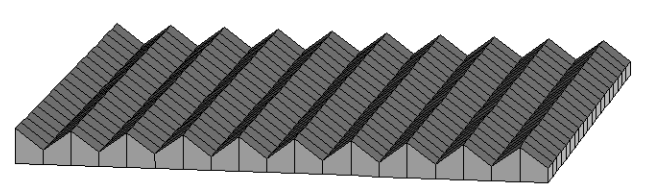

(f)

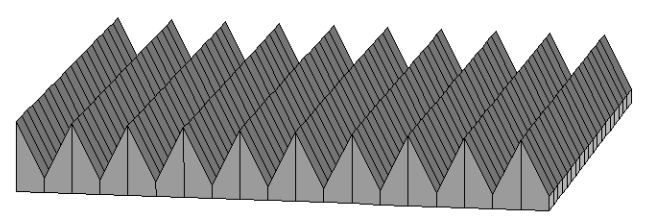

Figure 3. Performance of different indices of relief heterogeneity on the test-surfaces presented in Figure 2. "Index 1": Mean four point moving window standard deviation. "Index 2": Mean transect wise standard deviation. "Index 3": range of all measured elevations. "Index 4": transect wise length.

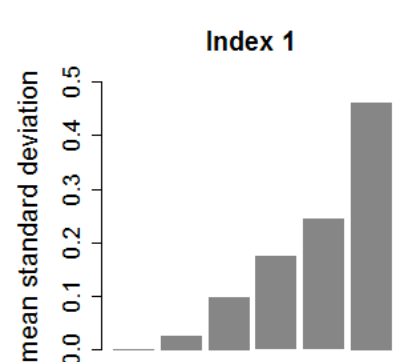

a) b) c) d) e) f) test surface

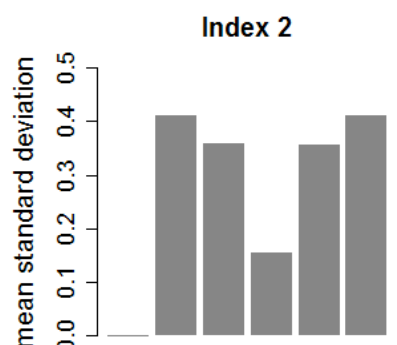

a) b) c) d) e) f) test surface

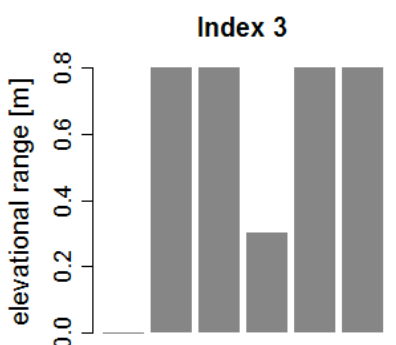

a) b) c) d) e) f) test surface

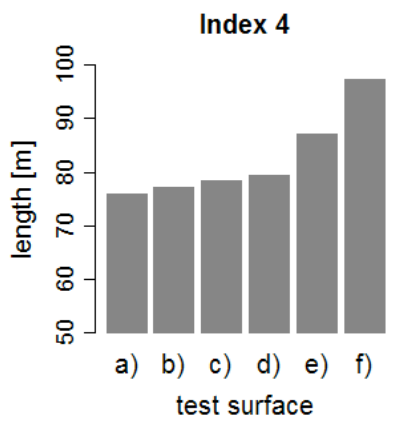

As the values of aspect are circular $\left(0-360^{\circ}\right)$, we calculated the cosine of all aspects to retrieve the non-circular variable "northernness" $(1=$ North $\ldots 0=$ East $\ldots-1=$ South $)$. Since all our plots were facing east we did not need to consider the corresponding "easternness".

\subsection{Analysis}

In order to analyse the effect of small-scale heterogeneity we fitted linear mixed effect models for the response variables species number of mosses, herbaceous and woody plants and their sum, the total species richness, respectively. We applied the lme function from the nlme R package v.3.1-100 [40]. 
Micro-relief heterogeneity, tree density and northernness were included as fixed factors, the altitudinal band as a random factor (Equation 2). For model fitting the restricted maximum log-likelihood was maximized. In order to test whether the vegetation type, namely laurel or pine forest, exhibited a significant confounding influence on our results, we fitted the same mixed effect models using the lmer function of the lme4 R package v.0.999375-42 [41], since the lme function does not allow for crossed random effects. Using AIC and $\chi^{2}$ test p-values of an ANOVA we then compared the models with altitudinal band as random factor with those constructed including both altitudinal band and vegetation type as random factors. Based on the same test criteria we conducted a stepwise forward model selection to test, which fixed and random factors resulted in the best model fit. The residuals were tested for normality using the Shapiro-Wilk's test as well as qq-plots. Where residuals were not normally distributed, which was the case for herbaceous and woody plants, the response variable was log-transformed resulting in normal distribution of the residuals. In order to evaluate the importance of small-scale heterogeneity for species richness in the different altitudinal bands, we applied variance partitioning on all response variables by means of the function varpart in the vegan package v.1.17-10 [42]. We did so for each altitudinal band separately. The explanatory variables for the linear model were micro-relief heterogeneity, tree density and northernness. Furthermore, we calculated the variance partitioning over all altitudinal bands by combining northernness and altitudinal band into one explanatory group. We report the proportion of explained variance calculated as adjusted $\mathrm{R}^{2}$. For $\mathrm{R}^{2}$ values close to zero the calculation of the adjusted $\mathrm{R}^{2}$ can occasionally result in negative values. Following Legendre [43] these are artefacts and are to be interpreted as zero explained variance. All data were analysed using R 2.13.0 [44].

\section{Results}

The number of plant species per plot varied from 3 to 18. Species richness within the four altitudinal bands was highly variable. However, differences between these bands were only significant between the lower pine forest and the laurel forest bands with the latter having a higher species richness (Figure 4, Tukey HSD, $\mathrm{p}<0.05$ ).

Figure 4. Cumulative mean species richness for mosses (dark grey), herbaceous (grey), and woody plants (light grey) per altitudinal band. Error bars refer to total species richness showing its standard deviation. Lower case letters indicate significant differences in total species richness (Tukey HSD, $\mathrm{p}<0.05$ ).

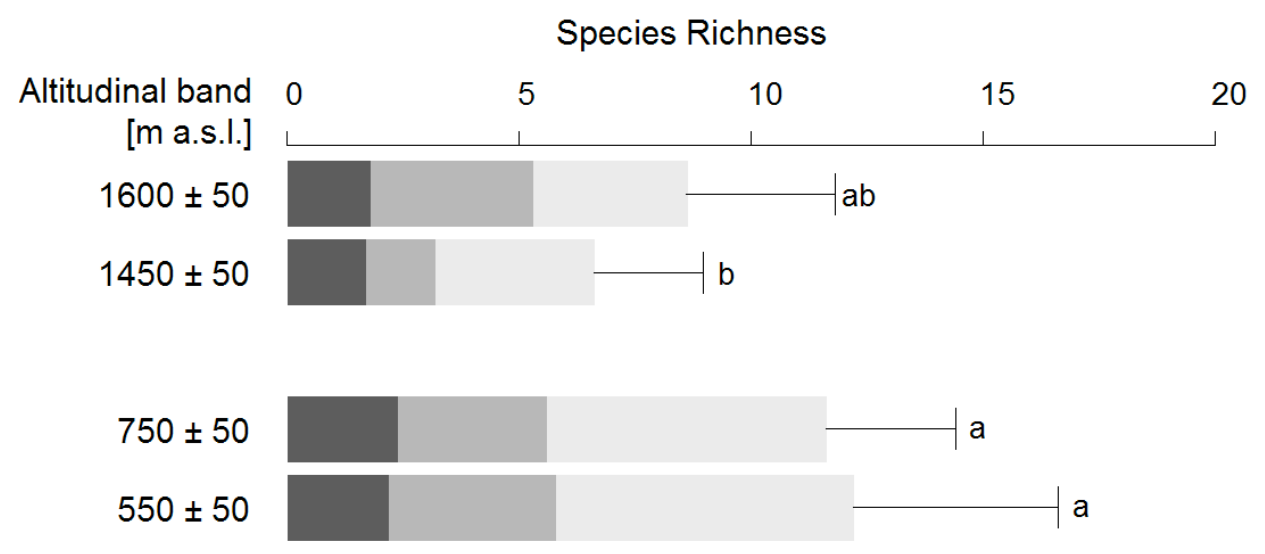


Among all collected parameters in the field study micro-relief heterogeneity, tree density and northernness were revealed as the best predictors in the linear mixed-effect model for total species richness. Total species richness was significantly affected by micro-relief heterogeneity, tree density and northernness (Table 1). However, the proportion of variance explained by micro-relief heterogeneity was relatively low (10\%) compared to tree density (20\%) and 'altitudinal band and northernness' (34\%; combined to one variable) (Figure 5).

Figure 5. Partitioning of the variation of total species richness between the explanatory variables tree density, a combined spatial variable based on northernness and altitudinal bands, and micro-relief heterogeneity. Overlapping bars indicate jointly explained variance [\%]. Non-overlapping parts depict explained variance explained only by a single variable.

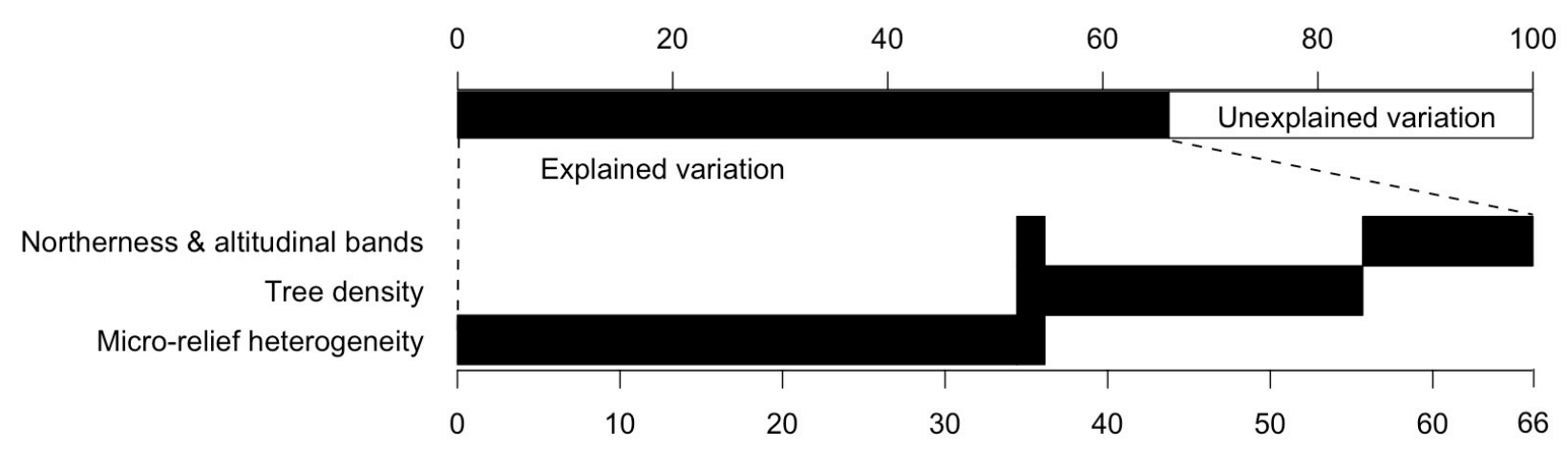

Linear mixed-effect models revealed different responses of growth forms to the explanatory variables (Table 1). Species richness of mosses was positively influenced by micro-relief heterogeneity. In contrast, tree density and northernness were both non-significant (Table 1). Herbaceous species richness showed no significant relationship to micro-relief heterogeneity, unlike the significant determinants tree density (regression estimator: $-0.064 \pm 0.009$, log-transformed) and northernness (regression estimator: $0.249 \pm 0.072$, log-transformed). The same applied to woody plants, which showed no significant response to micro-relief heterogeneity but significant responses to tree density (regression estimator: $-0.023 \pm 0.007$, log-transformed) and northernness (regression estimator: $0.111 \pm 0.049, \log$-transformed).

Table 1. Linear mixed-effects models of species richness (subdivided into mosses, herbaceous plants, woody plants and total species richness) and the corresponding environmental and spatial variables (micro-relief heterogeneity, tree density, northernness). The altitude was included as a random effect. Significant results $(p<0.05)$ are shown in bold. Df denotes the degrees of freedom.

\begin{tabular}{lcccc}
\hline \multirow{2}{*}{ Explanatory variable } & Mosses & Herbaceous plants & Woody plants & Total species richness \\
\cline { 2 - 5 } & $\boldsymbol{p}$ & $\boldsymbol{p}$ & $\boldsymbol{p}$ & $\boldsymbol{p}$ \\
\hline Micro-relief heterogeneity & $\mathbf{0 . 0 0 0 1}$ & 0.0926 & 0.1901 & $\mathbf{0 . 0 0 0 8}$ \\
Tree density & 0.0900 & $<\mathbf{0 . 0 0 0 1}$ & $\mathbf{0 . 0 0 1 5}$ & $<\mathbf{0 . 0 0 0 1}$ \\
Northernness & 0.8997 & $\mathbf{0 . 0 0 1 9}$ & $\mathbf{0 . 0 1 6 2}$ & $\mathbf{0 . 0 0 5 5}$ \\
\hline Df & 33 & 33 & 33 & 33 \\
\hline
\end{tabular}


In all but one case, including the vegetation type as additional random factor, the model fit based on AIC values did not improve and none of them were significantly different from each other $\left(\chi^{2}\right.$-test, mosses: $p=0.84$; herbaceous plants: $p=1$; woody plants: $p=0.13$; total species richness: $p=1)$. The model AIC was smaller only in the case of woody plants if vegetation type was included as random factor as compared to the previous model. Moreover, the stepwise forward model selection confirmed all models with micro-relief heterogeneity, tree-density and northernness as fixed factors and altitudinal band as random factor as the best models based on AIC values, except for woody plants. For the latter, the best model included only tree-density and northernness as fixed factors but both altitudinal band and vegetation type as crossed random factors.

The investigation of the relative importance of small-scale heterogeneity within the different altitudinal bands by variance partitioning, showed strong differences both within and between the growth forms (Figure 6). Within each altitudinal band the proportion of variance explained by micro-relief heterogeneity was highest for mosses (up to $66 \%$ at 550 m.a.s.1.). However, there was no clear pattern observable with respect to altitude when the whole gradient was analysed. Nevertheless, the two different forest types (laurel and pine forest) showed a tendency towards decreasing influence of habitat heterogeneity with increasing elevation. While overall explained variance by micro-relief heterogeneity was highest in the lowest altitudinal band, it decreased at 750 m.a.s.l., increased again at 1,450 m.a.s.l. and dropped to $20 \%$ towards the highest altitude. In contrast, micro-relief heterogeneity did not explain the variation in species richness patterns for herbaceous and woody plants, respectively.

Figure 6. Explained variation of species richness in percent (divided into mosses, herbaceous plants, woody plants and total species richness) by the explanatory variable micro-relief heterogeneity within the altitudinal bands.

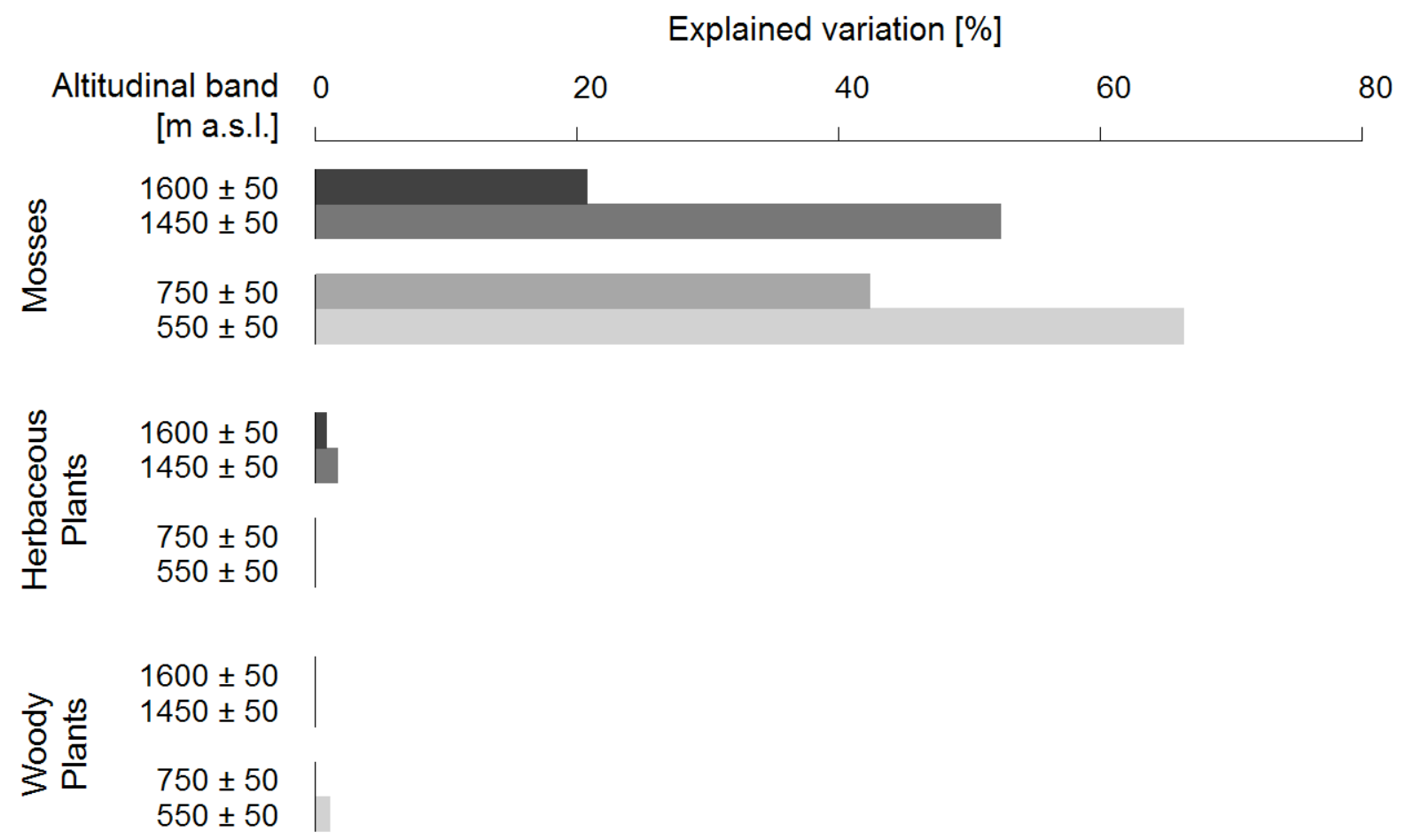




\section{Discussion}

Our aim was to identify general tendencies in the effect of micro-relief heterogeneity on plant species richness. The results show a significant influence of micro-relief heterogeneity on overall plant species richness, which is in accordance with other studies $[14,45,46]$. Yet, broken down into growth forms, we found significant relationships across altitudinal bands only for mosses. This partly confirms our hypothesis, where we expected micro-relief heterogeneity to influence species richness of mosses and herbaceous plants more strongly than in the case of woody plants. However, the hypothesis that the influence of micro-relief heterogeneity increases with altitude had to be rejected for all growth forms (Figure 6). This might be due to the fact that relief heterogeneity per se only explained a small part of the variance in total species richness (namely 10\%) and could therefore easily have been overlaid by other factors and processes such as tree density, anthropogenic disturbances, propagule pressure or patch size.

The chosen elevational gradient of more than 1,000 m covers a strong gradient in tree species composition. Commonly two main forest types (laurel and pine forest) are differentiated. However, inclusion of the forest type did not improve the models. Disentangling an effect of forest type and elevation is a non-trivial task as forest structure and tree species composition change along elevational gradients. Micro-relief heterogeneity could explain more than $60 \%$ of the variance in moss species richness. However, herbaceous and woody plants did not show any response in the linear mixed effect models. On the one hand this could be due to the unequal response of vegetation layers to environmental gradients [47], or on the other hand to the fact that plant growth forms differ in their ability to respond to fine-scale variation in abiotic heterogeneity [48].

Total species richness increased significantly with increasing small-scale relief-heterogeneity (Table 1). Considering that only mosses responded significantly, the significant relationship of total species richness has to be interpreted as mainly driven by this group.

The influence of heterogeneous micro-relief conditions on mosses was expected and also apparent during field sampling. However, such scale dependent responses have not yet been systematically proven. Surface depressions presumably provide more moist conditions as compared to flat surfaces. Rocks and boulders provide additional types of substrate. Species not occurring on soils may occur on the stony surfaces thus boosting species numbers. Additionally, in pine forests often only plots comprising heterogeneous micro-relief were not covered by thick pine needle litter. However, it was astonishing that there was no effect of northernness or tree density detectable on moss species richness, as mosses profit from moist conditions [49], which are more likely to be found under denser canopies or on north facing slopes under this climate.

Tree density and northernness were found to serve as significant predictors for herbaceous and woody plants. In both cases species-poor plots were related to higher tree density, causing thick litter layers and shade, which might have prevented seedling establishment of other species. Northernness relates to aspect and in our case more precisely to the degree of potential irradiation: the lower the value for northernness, the higher the insolation, neglecting changes due to the diurnally changing influence of the trade-wind induced stratocumulus layer. In all cases the regression estimator for northernness was positive, which means that aspects with higher insolation host less species. This was especially unexpected for the herbaceous plants, as herbaceous richness generally profits from 
increased insolation in forests [50]. However, in the pine forests, where precipitation is a limiting factor for plant growth [51], the increased species richness on north-facing slopes might be explained by increased soil moisture found on north-facing plots.

In this study the scale of heterogeneity was chosen to be smaller than the spatial extent of individual woody plants, this scale may have been too fine for detection of relief effects on woody plants. As in a survey on the influence of spatial nutrient heterogeneity on species richness, Hutchings et al. [52] only found significant effects when the size of individual plants was smaller than the measured scale. As the scale of observation (i.e., $1 \mathrm{~m}$ ) encompassed the actual size of the remaining growth forms and their presumed spatial range of influence, it can be assumed appropriate to detect the effect of relief heterogeneity on mosses and herbaceous plants.

Whether the applied spatial resolution was sufficient, remains to be tested. Hofer et al. [10] labelled their $25 \mathrm{~m}^{2}$ plots "microsites", which highlights the fact that even smaller resolutions are often not considered as being ecologically important. Our study emphasises that this assumption must be reconsidered. Heterogeneity is expected to act on different scales, especially when comparing growth forms as diverse as mosses and trees. Thus, we cannot conclude that heterogeneity per se does not affect plant richness of herbaceous or woody plants. This may depend on the grain and extent of studies [53]. For an investigation of such scale specific effects, studies with a nested plot design might be an appropriate approach.

A further factor masking the effect of micro-relief heterogeneity on herbaceous and woody species richness could have been the geographical isolation of the island, which limits the potential number of species able to colonize our plots (sensu [54]) and thus modifies the often found relationship between heterogeneity and diversity (e.g. [12]). Kadmon and Allouche [55] showed that the theory of island biogeography alters the relationship predicted by the niche theory.

We concentrated on forested ecosystems, where differences in micro-climate are expected to be small owing to limited insolation through dense canopies [56]. In open environments differences in micro-climate are likely to be more pronounced [5]. Nevertheless, the very fact that micro-climate does not mask other micro-relief induced factors such as the increase in surface availability per plot, the increase in substrate types or the small-scale variability in soil moisture, makes this analysis worthwhile. Moreover, as the growth form of mosses has shown, there is indeed an influence of micro-relief heterogeneity on species richness despite presumably moderate changes in microclimate.

\section{Conclusions}

In forest ecosystems of La Palma the species richness of various plant growth forms responds differently to surface structure. Only mosses respond directly to small-scale micro-relief heterogeneity, which increases the diversity of small-scale ecological niches independent of altitude. For small plants, such as mosses, bioclimatic envelope models might be based on too broad assumptions, even if local effects may by dampened on a larger scale [57]. However, for herbaceous and woody plants small-scale micro-relief heterogeneity does not contribute to an improved explanation of species richness patterns. For these species, general site conditions can be applied. Our results stress the fact that the role of relief heterogeneity has to be considered separately and specifically for different groups of organisms. There is no overarching relationship between relief heterogeneity and species richness 
across scales and plant growth forms. However, the influence of heterogeneity on herb, shrub and tree richness may vary with spatial resolution (grain size). Modern technology such as laser scanners may facilitate area-wide data collection and provide an opportunity to test this hypothesis. As species distribution models are a common predictive tool used for decision-making in nature conservation and for facing threats caused by climate change, an improved knowledge of the underlying ecological principles is crucial. Current modelling results might be strongly biased for species groups with small-scale habitats.

\section{Acknowledgments}

The study was supported by the "Global Change Ecology (M.Sc.)" study program within the Elite Network of Bavaria.

\section{References}

1. Parmesan, C.; Yohe, G. A globally coherent fingerprint of climate change impacts across natural systems. Nature 2003, 421, 37-42.

2. Feeley, K.J.; Silman, M.R.; Bush, M.B.; Farfan, W.; Cabrera, K.G.; Malhi, Y.; Meir, P.; Revilla, N.S.; Quisiyupanqui, M.N.R.; Saatchi, S. Upslope migration of Andean trees. J. Biogeogr. 2011, 38, 783-791.

3. Thomas, C.D.; Cameron, A.; Green, R.E.; Bakkenes, M.; Beaumont, L.J.; Collingham, Y.C.; Erasmus, B.F.N.; de Siqueira, M.F.; Grainger, A.; Hannah, L.; et al. Extinction risk from climate change. Nature 2004, 427, 145-148.

4. Suggitt, A.J.; Gillingham, P.K.; Hill, J.K.; Huntley, B.; Kunin, W.E.; Roy, D.B.; Thomas, C.D. Habitat microclimates drive fine-scale variation in extreme temperatures. Oikos 2011, 120, 1-8.

5. Scherrer, D.; Körner, C. Infra-red thermometry of alpine landscapes challenges climatic warming projections. Glob. Change Biol. 2010, 16, 2602-2613.

6. Alcamo, J.; Moreno, J.M.; Nováky, B.; Bindi, M.; Corobov, R.; Devoy, R.J.N.; Giannakopoulos, C.; Martin, E.; Olesen, J.E.; Shvidenko, A. Climate Change 2007-Impacts, Adaptation and Vulnerability. Working Group II Contribution to the Fourth Assessment Report of the IPCC; Parry, M.L., Canziani, O.F., Palutikof, J.P., van der Linden, P.J., Hanson, C.E., Eds.; Cambridge University Press: Cambridge, UK, 2007; pp 541-580.

7. Scherrer, D.; Körner, C. Topographically controlled thermal-habitat differentiation buffers alpine plant diversity against climate warming. J. Biogeogr. 2011, 38, 406-416.

8. Hutchinson, G.E. Population studies-Animal ecology and demography_Concluding remarks. Cold Spring Harb. Symp. Quant. Biol. 1957, 22, 415-427.

9. Burnett, M.R.; August, P.V.; Brown, J.H.; Killingbeck, K.T. The influence of geomorphological heterogeneity on biodiversity I. A patch-scale perspective. Conserv. Biol. 1998, 12, 363-370.

10. Hofer, G.; Wagner, H.H.; Herzog, F.; Edwards, P.J. Effects of topographic variability on the scaling of plant species richness in gradient dominated landscapes. Ecography 2008, 31, 131-139.

11. Müller, C.; Berger, G.; Glemnitz, M. Quantifying geomorphological heterogeneity to assess species diversity of set-aside arable land. Agric. Ecosyst. Environ. 2004, 104, 587-594. 
12. Lundholm, J.T. Plant species diversity and environmental heterogeneity: Spatial scale and competing hypotheses. J. Veg. Sci. 2009, 20, 377-391.

13. Loneragan, W.A.; Delmoral, R. The influence of microrelief on community structure of subalpine meadows. Bull. Torrey Bot. Club 1984, 111, 209-216.

14. Beatty, S.W. Influence of microtopography and canopy species on spatial patterns of forest understory plants. Ecology 1984, 65, 1406-1419.

15. da Silva, W.G.; Metzger, J.P.; Bernacci, L.C.; Catharino, E.L.M.; Durigan, G.; Simoes, S. Relief influence on tree species richness in secondary forest fragments of Atlantic Forest, SE, Brazil. Acta Bot. Bras. 2008, 22, 589-598.

16. Suchodoletz, H.V.; Glaser, B.; Thrippleton, T.; Broder, T.; Zang, U.; Eigenmann, R.; Kopp, B.; Reichert, M.; Zöller, L. The influence of Saharan dust deposits on La Palma soil properties (Canary Islands, Spain). Catena 2011, in press.

17. Resler, L.M.; Butler, D.R.; Malanson, G.P. Topographic shelter and conifer establishment and mortality in an alpine environment, Glacier National Park, Montana. Phys. Geogr. 2005, 26, $112-125$.

18. Debski, I.; Burslem, D.; Palmiotto, P.A.; Lafrankie, J.V.; Lee, H.S.; Manokaran, N. Habitat preferences of Aporosa in two Malaysian forests: Implications for abundance and coexistence. Ecology 2002, 83, 2005-2018.

19. Palmer, M.W.; White, P.S. Scale dependence and the species-area relationship. Am. Nat. 1994, $144,717-740$.

20. White, P.S.; Jentsch, A. The search for generality in studies of disturbance and ecosystem dynamics. In Progress in Botany; Esser, K., Lüttke, U., Kadereit, J.W., Beyschlag, W., Eds.; Springer: Berlin, Germany, 2001; volume 62, pp. 399-450.

21. Linhart, Y.B.; Grant, M.C. Evolutionary significance of local genetic differentiation in plants. Annu. Rev. Ecol. Syst. 1996, 27, 237-277.

22. Decocq, G. Patterns of plant species and community diversity at different organization levels in a forested riparian landscape. J. Veg. Sci. 2002, 13, 91-106.

23. Triantis, K.A.; Sfenthourakis, S. Island biogeography is not a single-variable discipline: The small island effect debate. Div. Distrib. 2011, 18, 92-96.

24. Whittaker, R.J.; Ladle, R.J.; Araujo, M.B.; Fernandez-Palacios, J.M.; Delgado, J.D.; Arevalo, J.R. The island immaturity-Speciation pulse model of island evolution: An alternative to the “diversity begets diversity" model. Ecography 2007, 30, 321-327.

25. Steinbauer, M.J.; Otto, R.; Naranjo-Cigala, A.; Beierkuhnlein, C.; Fernaández-Palacios, J.-M. Increase of island endemism with altitude-Speciation processes on oceanic islands. Ecography 2012, 35, 23-32.

26. Coblentz, D.D.; Riitters, K.H. Topographic controls on the regional-scale biodiversity of the south-western USA. J. Biogeogr. 2004, 1125-1138.

27. Reyes-Betancort, J.A.; Guerra, A.S.; Guma, I.R.; Hurnphries, C.J.; Carine, M.A. Diversity, rarity and the evolution and conservation of the Canary Islands endemic flora. An. Jard. Bot. Madr. 2008, 65, 25-45.

28. Steinbauer, M.J.; Beierkuhnlein, C. Characteristic pattern of species diversity on the Canary Islands. Erdkunde 2010, 64, 57-71. 
29. Fernandez-Palacios, J.M.; de Nicolas, J.P. Altitudinal pattern of vegetation variation on Tenerife. J. Veg. Sci. 1995, 6, 183-190.

30. Varela, A.M. Comparison of the aerosol index from satellites and the atmospheric extinction coefficient above the Canarian observatories. 2004, 5489, 245-255.

31. Irl, S.D.H.; Beierkuhnlein, C. Distribution of endemic plant species on an oceanic island-A geospatial analysis of La Palma (Canary Islands). Procedia Environ. Sci. 2011, 7, 170-175.

32. Arechavaleta, M.; Rodriguez, S.; Zurita, N.; Garcia, A. Lista de Especies Silvestres de Canarias. Hongas, Plantas y Animales Terrestres; Gobierno de Canarias.: Santa Cruz de Tenerife, Spain, 2010; p. 579.

33. Wilson, J.B. Cover plus: Ways of measuring plant canopies and the terms used for them. J. Veg. Sci. 2011, 22, 197-206.

34. Saleh, A. Soil roughness measurement-Chain method. J. Soil Water Conserv. 1993, 48, 527-529.

35. Dragut, L.; Eisank, C.; Strasser, T. Local variance for multi-scale analysis in geomorphometry. Geomorphology 2011, 130, 162-172.

36. Grohmann, C.H.; Smith, M.J.; Riccomini, C. Multiscale analysis of topographic surface roughness in the Midland Valley, Scotland. IEEE Trans. Geosci. Remote Sens. 2011, 49, 1200-1213.

37. Glenn, N.F.; Streutker, D.R.; Chadwick, D.J.; Thackray, G.D.; Dorsch, S.J. Analysis of LiDAR-derived topographic information for characterizing and differentiating landslide morphology and activity. Geomorphology 2006, 73, 131-148.

38. Haneberg, W.C.; Creighton, A.L.; Medley, E.W.; Jonas, D.A. Use of LiDAR to assess slope hazards at the Lihir gold mine, Papua New Guinea; CD-RPM. In Proceedings of the International Conference on Landslide Risk Management; Hungr, O., Fell, R., Couture, R., Eberhardt, E., Eds.; Vancouver, Canada, 31 May-3 June 2005.

39. Forman, R.T.T. Land Mosaics: The Ecology of Landscapes and Regions; Cambridge University Press: Cambridge, UK, 1995.

40. Pinheiro, J.; Bates, D.; DebRoy, S.; Sarkar, D. nlme: Linear and Nonlinear Mixed Effects Models; 3.1-100 version; 2011. Available online: http://cran.r-project.org/web/packages/nlme/index.html (accessed on 30 November 2011).

41. Bates, D.; Maechler, M.; Bolker, B. Ime4: Linear Mixed-Effects Models Using S4 Classe; 0.999375-42 version; 2011. Available online: http://cran.r-project.org/web/packages/lme4/ index.html (accessed on 30 November 2011).

42. Oksanen, J.; Blanchet, F.; Kindt, G.; Legendre, R.; O’Hara, R.B.; Simpson, G.L. Vegan: Community Ecology Package; 1.17-10 version; 2011. Available online: http://cran.rproject.org/web/packages/vegan/index.html (accessed on 30 November 2011).

43. Legendre, P. Studying beta diversity: Ecological variation partitioning by multiple regression and canonical analysis. J. Plant Ecol. UK 2008, 1, 3-8.

44. R Development Core Team; $R: A$ Language and Environment for Statistical Computing; R Foundation for Statistical Computing: Vienna, Austria, 2011. Available online: http://www.Rproject.org (accessed on 30 November 2011).

45. Johnson, M.P.; Frost, N.J.; Mosley, M.W.J.; Roberts, M.F.; Hawkins, S.J. The area-independent effects of habitat complexity on biodiversity vary between regions. Ecol. Lett. 2003, 6, 126-132. 
46. Kuntz, K.L.; Larson, D.W. Microtopographic control of vascular plant, bryophyte and lichen communities on cliff faces. Plant Ecol. 2006, 185, 239-253.

47. Lyon, J.; Sagers, C.L. Structure of herbaceous plant assemblages in a forested riparian landscape. Plant Ecol. 1998, 138, 1-16.

48. Decocq, G. The 'masking effect' of silviculture on substrate-induced plant diversity in oak-hornbeam forests from Northern France. Biodivers. Conserv. 2000, 9, 1467-1491.

49. Almufti, M.M.; Sydes, C.L.; Furness, S.B.; Grime, J.P.; Band, S.R. Quantitative-analysis of shoot phenology and dominance in herbaceous vegetation. J. Ecol. 1977, 65, 759-791.

50. Anderson, K.L.; Leopold, D.J. The role of canopy gaps in maintaining vascular plant diversity at a forested wetland in New York State. J. Torrey Bot. Soc. 2002, 129, 238-250.

51. Nezadal, W.; Lindacher, R.; Welss, W. Local endemic plant species and phytodiversity of Western Canary Islands La Pama and La Gomera. Feddes Repert. 1999, 110, 19-30.

52. Hutchings, M.J.; John, E.A.; Wijesinghe, D.K. Toward understanding the consequences of soil heterogeneity for plant populations and communities. Ecology 2003, 84, 2322-2334.

53. Steinbauer, M.J.; Dolos, K.; Reineking, B.; Beierkuhnlein, C. Current measures for distance decay in similarity of species composition are influenced by study extent and grain size. Glob. Ecol. Biogeogr. 2012, in press.

54. Macarthur, R.H.; Wilson, E.O. The Theory of Island Biogeography. Monographs in Population Biology; Princeton University Press: Princeton, NJ, USA, 1967.

55. Kadmon, R.; Allouche, O. Integrating the effects of area, isolation, and habitat heterogeneity on species diversity: A unification of island biogeography and niche theory. Am. Nat. 2007, 170, 443-454.

56. Paulsen, J.; Korner, C. GIS-analysis of tree-line elevation in the Swiss Alps suggests no exposure effect. J. Veg. Sci. 2001, 12, 817-824.

57. Leuzinger, S.; Luo, Y.Q.; Beier, C.; Dieleman, W.; Vicca, S.; Korner, C. Do global change experiments overestimate impacts on terrestrial ecosystems? Trends Ecol. Evol. 2011, 26, 236-241.

(C) 2012 by the authors; licensee MDPI, Basel, Switzerland. This article is an open access article distributed under the terms and conditions of the Creative Commons Attribution license (http://creativecommons.org/licenses/by/3.0/). 